\title{
Lifestyle Factors as Risk Factors for Fatigue and Psychological Distress in the Working Population. Prospective Results From the Maastricht Cohort Study.
}

Citation for published version (APA):

Bültmann, U., Kant, Y., Kasl, S. V., Schröer, C. A. P., Swaen, G. M. H., \& van den Brandt, P. A. (2002). Lifestyle Factors as Risk Factors for Fatigue and Psychological Distress in the Working Population. Prospective Results From the Maastricht Cohort Study. Journal of Occupational and Environmental Medicine, 44, 116-124. https://doi.org/10.1097/00043764-200202000-00006

Document status and date:

Published: 01/01/2002

DOI:

10.1097/00043764-200202000-00006

Document Version:

Publisher's PDF, also known as Version of record

Please check the document version of this publication:

- A submitted manuscript is the version of the article upon submission and before peer-review. There can be important differences between the submitted version and the official published version of record. People interested in the research are advised to contact the author for the final version of the publication, or visit the DOI to the publisher's website.

- The final author version and the galley proof are versions of the publication after peer review.

- The final published version features the final layout of the paper including the volume, issue and page numbers.

Link to publication

\footnotetext{
General rights rights.

- You may freely distribute the URL identifying the publication in the public portal. please follow below link for the End User Agreement:

www.umlib.nl/taverne-license

Take down policy

If you believe that this document breaches copyright please contact us at:

repository@maastrichtuniversity.nl

providing details and we will investigate your claim.
}

Copyright and moral rights for the publications made accessible in the public portal are retained by the authors and/or other copyright owners and it is a condition of accessing publications that users recognise and abide by the legal requirements associated with these

- Users may download and print one copy of any publication from the public portal for the purpose of private study or research.

- You may not further distribute the material or use it for any profit-making activity or commercial gain

If the publication is distributed under the terms of Article 25fa of the Dutch Copyright Act, indicated by the "Taverne" license above, 


\section{Lifestyle Factors as Risk Factors for Fatigue and Psychological Distress in the Working Population: Prospective Results From the Maastricht Cohort Study}

Ute Bültmann, MSc

\author{
IJmert Kant, PhD
}

Stanislav V. Kasl, PhD

Kees A. P. Schröer, PhD

Gerard M. H. Swaen, PhD

Piet A. van den Brandt, PhD

We examined potentially modifiable lifestyle factors as possible risk factors for the onset of fatigue and psychological distress after 1-year follow-up among 8833 employees who participated in the prospective Maastricht Cohort Study of "Fatigue at Work." Results showed, even after adjustment for demographics, presence of disease, other lifestyle factors, psychosocial work characteristics, and psychological distress, that overweight (body mass index, 25 to 29.9) and being physically inactive during leisure time were strongly related to onset of fatigue in men, whereas underweight (body mass index, <18.5) in women increased the risk for future fatigue. In addition, the study suggests some differential effects of lifestyle factors in the onset of psychological distress. Certainly, these modifiable factors can be targeted in interventions, either on an individual or group level, to prevent or at least reduce the risk of developing fatigue and psychological distress in the working population. (J Occup Environ Med. 2002;44:116-124)

From the Department of Epidemiology (Ms Bültmann, Dr Kant, Dr Swaen, Dr van den Brandt) and the Department of Medical Sociology (Dr Schröer), Maastricht University; and the Department of Epidemiology and Public Health, Yale University School of Medicine (Dr Kasl).

Address correspondence to: Ute Bültmann, MSc, Department of Epidemiology, Maastricht University, PO Box 616, 6200 MD Maastricht, The Netherlands; u.bultmann@epid.unimaas.nl.

Copyright $(C)$ by American College of Occupational and Environmental Medicine atigue in the working population, although recognized in previous studies, ${ }^{1-4}$ has recently attracted attention in occupational (mental) health research, because it may interfere with an individual's performance and functioning in the occupational and in the home setting. Moreover, because fatigue may also lead to sickness absenteeism and work disability, ${ }^{5}$ it is not only a pressing social problem but also an economic problem calling for preventive action.

In the literature, the likely multifactorial etiology of fatigue is emphasized, ${ }^{6}$ and "psychosocial" reasons (eg, work, family, and lifestyle) are most often mentioned as explanations for feeling fatigued. ${ }^{7}$ To date, research has mainly focused on the relationship between work characteristics and fatigue. ${ }^{3,8}$ Longitudinal analyses conducted within the Maastricht Cohort Study, a largescale epidemiological study of "Fatigue at Work," revealed that psychosocial work characteristics are predictive of fatigue after 1-year follow-up. ${ }^{9}$ Although previous studies have shown that lifestyle factors, such as smoking, alcohol consumption, and physical activity during leisure time, and related variables such as body mass index, may affect the (mental) health status ${ }^{1,10,11}$ and may be regarded as possible risk factors, information is sparse about lifestyle factors and the risk of fatigue in the working population. A cross-sec- 
tional study among 3785 Israeli industrial employees showed that "not being physically active during leisure time" was associated with severe fatigue (odds ratio [OR], 1.7; 95\% confidence interval $[\mathrm{CI}], 1.3$ to 2.3 ), that more complaints of severe fatigue were found among employees who smoked 10 or more cigarettes per day, and that no relation was found between body mass index or alcohol consumption and fatigue. ${ }^{1}$ Of course, cross-sectional associations, particularly the relationship between physical activity and fatigue, are difficult to interpret for direction of influence. To our knowledge, prospective relations between lifestyle factors and fatigue in the working population are not yet established. For the development of preventive measures, however, it is important to examine the etiological role of potentially modifiable lifestyle factors in the onset of fatigue.

In the Maastricht Cohort Study, fatigue was fairly well associated with psychological distress, as expressed by a correlation of $0.62 .^{12}$ This finding, which is consistent with observed correlations in other studies, ${ }^{3,7,13}$ has led to questions such as: Is fatigue conceptually and etiologically distinct from psychological distress? Or is the overlap between the two constructs so large as to throw in doubt the usefulness of having two separate concepts? In the research literature on prolonged fatigue, several recent studies have addressed operational and conceptual issues regarding fatigue and different psychiatric disorders. ${ }^{14-17}$ While discussing competing hypotheses about the temporal relationship and differences between fatigue and psychiatric disorder in the literature, Addington et $\mathrm{al}^{17}$ concluded that the findings further substantiate the idea that fatigue is etiologically heterogeneous from psychiatric disturbances. At present, longitudinal analyses suggest some differential predictive effects of psychosocial work characteristics in the etiology of fatigue versus psychological distress, mea- sured with the Checklist Individual Strength and the General Health Questionnaire, supporting the notion of two distinct concepts. ${ }^{9}$ With respect to lifestyle factors, little is known about differential etiological effects regarding fatigue and psychological distress.

In the present study, we used the data of the Maastricht Cohort Study to prospectively explore the role of lifestyle factors (smoking, alcohol consumption, physical activity during leisure time, and the associated variable of body mass index), measured at baseline, in the onset of fatigue and psychological distress after 1-year follow-up in the working population, thereby further elucidating the concepts of fatigue and psychological distress.

\section{Methods}

\section{Study Population at Baseline and Follow-Up}

The large-scale prospective Maastricht Cohort Study of "Fatigue at work" was set up to examine the onset and natural history of fatigue and psychological distress in the working population. ${ }^{18,19}$ In May 1998, 26,978 employees, aged 18 to 65 years, from 45 companies and organizations received an introductory letter at home and the baseline questionnaire. This self-administered baseline questionnaire included items on psychosocial work characteristics, demographic, work-family, lifestyle, and health factors and on fatigue and psychological distress. A total of 12,161 employees completed and returned the questionnaire. The overall response rate was $45 \%$. Written consent was obtained from all participants. Sixty-six questionnaires were excluded from the analysis because the age criterion was not met or because of technical reasons. The baseline cohort consisted of 8840 men $(73 \%)$ and 3255 women (27\%). Full details of the sampling, the nonresponse, and the baseline characteristics of the study population have been reported elsewhere. ${ }^{12}$
In May 1999, those employees ( $n$ $=11,272$ ) who had completed the baseline questionnaire and at least one of the two short questionnaires, which were sent in September 1998 and January 1999, were approached again to complete the follow-up questionnaire. Overall, 9625 employees - 7025 men $(73 \%)$ and 2600 women $(27 \%)$ - completed and returned the follow-up questionnaire (response rate of 80\%). In the present analysis, those employees who reported themselves at baseline absent from work or reported working under modified conditions related to former sickness absence (eg, fewer hours, modified tasks, or other functions) were excluded. Therefore, the final study population on whom follow-up data were available was 8833 employees, 6522 men (74\%) and 2311 women (26\%).

\section{Baseline Lifestyle Factors}

The body mass index (BMI) was calculated from information on weight and height $\left(B M I=\mathrm{kg} / \mathrm{m}^{2}\right)$. The BMI was used as continuous variable and then categorized according to the standardized classification of the National Institutes of Health (BMI <18.5, underweight; BMI 18.5 to 24.9 , normal; BMI 25 to 29.9, overweight; BMI 30 to 34.9, obesity I; BMI 35 to 39.9, obesity II; BMI $\geq 40$, extreme obesity III). ${ }^{20}$ Because small numbers of employees were observed in the obese subgroups, we recorded BMI into four categories (BMI $<18.5$, underweight; BMI 18.5 to 24.9 , normal; BMI 25 to 29.9, overweight; BMI $\geq 30$, obesity). Alcohol consumption was measured by weekly consumption in glasses and divided into four categories ( 0 glasses, 1 to 14 glasses, 15 to 21 glasses, $\geq 22$ glasses/week). Smoking status was assessed by a single item ("Do you smoke every day?"). Physical activity during leisure time was measured by a single item ("How many times per week are you at least half an hour physically active?"). The response options were (never/once a week, 2 to 7 times a 
TABLE 1

Lifestyle Factors and Prevalence of Fatigue and Psychological Distress at Baseline ${ }^{a}$

\begin{tabular}{|c|c|c|c|c|c|c|c|c|}
\hline & \multicolumn{4}{|c|}{ Men $(n=8840)$} & \multicolumn{4}{|c|}{ Women $(n=3255)$} \\
\hline & $n$ & $\%$ & $\% F$ & $\%$ PD & $n$ & $\%$ & $\% F$ & $\% \mathrm{PD}$ \\
\hline Overall prevalence & & & 21.7 & 21.8 & & & 22.5 & 25.9 \\
\hline $\mathrm{BMI}$ & & & 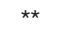 & * & & & & \\
\hline Underweight $(<18.5)$ & 33 & 0.4 & 27.3 & 24.2 & 83 & 2.6 & 28.8 & 32.5 \\
\hline Normal (18.5-24.9) & 4212 & 49.2 & 20.6 & 21.5 & 2156 & 68.9 & 21.3 & 25.7 \\
\hline Overweight (25-29.9) & 3722 & 43.5 & 22.1 & 21.6 & 695 & 22.1 & 23.5 & 25.0 \\
\hline Obesity I (30-34.9) & 509 & 5.9 & 27.0 & 26.9 & 174 & 5.5 & 28.4 & 29.0 \\
\hline Obesity II (35-39.9) & 60 & 0.7 & 23.3 & 25.0 & 34 & 1.1 & 18.2 & 23.5 \\
\hline Obesity III ( $\geq 40)$ & 21 & 0.2 & 23.8 & 28.6 & 7 & 0.2 & 42.9 & 57.1 \\
\hline Alcohol & & & $\star \star$ & & & & * & \\
\hline No alcohol & 1797 & 20.3 & 24.7 & 23.9 & 1425 & 44.0 & 24.8 & 24.9 \\
\hline 1-14 glasses/week & 5757 & 65.1 & 20.7 & 21.3 & 1691 & 52.2 & 20.3 & 26.5 \\
\hline 15-21 glasses/week & 891 & 10.1 & 21.3 & 20.8 & 109 & 3.4 & 25.9 & 26.6 \\
\hline$\geq 22$ glasses/week & 338 & 3.8 & 23.2 & 22.6 & 13 & 0.4 & 38.5 & 38.5 \\
\hline Smoking daily & & & $\star *$ & $\star \star$ & & & $\star *$ & $\star \star$ \\
\hline No & 6388 & 72.7 & 20.8 & 20.8 & 2320 & 71.7 & 20.1 & 23.2 \\
\hline Yes & 2396 & 27.3 & 24.0 & 24.7 & 916 & 28.3 & 28.6 & 32.6 \\
\hline Physical activity & & & $\star \star$ & $\star \star \star$ & & & $* \star$ & $\star \star$ \\
\hline 0-1 time/week & 2953 & 33.6 & 30.3 & 25.1 & 1032 & 32.0 & 30.3 & 30.6 \\
\hline 2-7 times/week & 5203 & 59.2 & 17.6 & 20.3 & 2006 & 62.0 & 19.0 & 23.2 \\
\hline$>7$ times/week & 633 & 7.2 & 15.3 & 18.7 & 195 & 6.0 & 17.2 & 26.9 \\
\hline
\end{tabular}

${ }^{\mathrm{a}} \mathrm{F}$, prevalence of fatigue; PD, prevalence of psychological distress; BMI, body mass index.

${ }^{*} P<0.05$ for differences in proportions by chi-squared statistics.

${ }^{\star *} P<0.01$ for differences in proportions by chi-squared statistics.

week, $>7$ times week). Table 1 shows the distribution of lifestyle factors at baseline for men and women separately.

\section{Baseline Psychosocial Work Characteristics, Demographic and Health Factors}

A validated Dutch version of the Job Content Questionnaire was used to measure psychological demands, decision latitude, and social support at work. ${ }^{21,22}$ Psychological demands were assessed by the sum of five items. Decision latitude was measured by the sum of two subscales: skill discretion and decision authority. Social support was assessed by two scales, each consisting of four items: supervisor support and coworker support. Emotional demands at work were measured by the sum of five items, which were derived from a Dutch questionnaire on Work and Health, ${ }^{23}$ a Dutch questionnaire on Perception and Judgement of Work, ${ }^{24}$ and self-formulated. To assess whether employees perceive their work as physically demanding, a single item from the Dutch questionnaire on Work and Health ${ }^{23}$ was used. Three items from the Dutch questionnaire on Perception and Judgement of Work ${ }^{24}$ were used to measure job insecurity, conflicts with supervisor, and conflicts with coworkers. Employees provided information on age, educational level, living alone, status of employment (permanent or temporary contract), and the presence of disease. Details of these measures, which are considered in the analyses as confounding factors, have been reported elsewhere. . $^{8}$

\section{Baseline and Follow-Up of Fatigue}

The 20-item self-report Checklist Individual Strength (CIS), which was originally developed for hospital studies of chronic fatigue syndrome, was used to measure fatigue. ${ }^{25,26}$ The CIS covers several aspects of fatigue, such as severity, concentration, motivation, and physical activity level. The instrument was extensively tested in the clinical setting ${ }^{27,28}$ and was validated in the working population. ${ }^{29}$ Subjects are instructed to indicate how they felt during the past 2 weeks. The response to each statement is scored on a seven-point Likert scale ( $1=$ "Yes, that is true" to $7=$ "No, that is not true"). Higher scores indicate a higher level of fatigue, more concentration problems, reduced motivation, or low levels of activity. In the Maastricht Cohort Study, the responses to the individual items were summed to generate a CIS total score, ranging from 20 to 140 . A cutoff point for case classification of CIS total $>76$ was established in a separate pilot study by means of defined samples with differences in fatigue levels. ${ }^{19}$ All employees scoring $>76$ were designated as probable fatigue cases.

\section{Baseline and Follow-Up Psychological Distress}

The 12-item version of the General Health Questionnaire (GHQ-12) was used to assess psychological distress. ${ }^{30,31}$ The GHQ-12 was devel- 
oped as a screening instrument for detecting minor psychiatric disorders in the general population. Two scoring systems were used for the fourpoint response scale. The Likert scoring method $(0,1,2,3)$ summed the responses of the 12 items to generate a continuous distribution, ranging from 0 to 36. The traditional GHQ scoring method $(0,0,1,1)$ is designed to identify individuals reporting sufficient psychological distress to be classified as probable cases of minor psychiatric disorder. In the present study, the threshold for case classification was 4 or higher, given a possible range of scores from 0 to 12 , which means that employees scoring 4 or more of the 12 items were considered to represent probable cases of psychological distress. The threshold for case classification is high but identical to the threshold used in other workplace studies. ${ }^{3,32}$

\section{Data Analytic Procedure}

All analyses were performed separately for men and women because of the observed gender difference regarding psychological distress ${ }^{12}$ and because our earlier reports of results $^{9,12}$ were gender-specific. Differences in the prevalence of fatigue and psychological distress between categories of lifestyle factors were assessed by chi-squared statistics. Pearson intercorrelations were computed for all study variables. After exclusion of either fatigue cases (CIS > 76) or psychological distress cases (GHQ $\geq 4$ ) at baseline, the cumulative 1-year incidence of fatigue and psychological distress was determined. To examine the role of lifestyle factors, measured at baseline, in the onset of fatigue and psychological distress after 1-year follow-up, the data were analyzed using multiple logistic regression analysis. Statistical analyses were performed using the Statistical Package for the Social Sciences, release 9.0. ${ }^{33}$

Multiple logistic regression was conducted in four steps for each lifestyle factor separately. Because a simple incidence analysis ignores the issue that those close to the CIS cutoff and making only small changes will be counted as incident cases, we introduced the refinement that they also must have an increase of a certain size. The size was determined by calculating the mean within-person variance for baseline and follow-up CIS measurement (eight points). Then the delta CIS score, which is the follow-up CIS score minus the baseline CIS score, was calculated for all employees. Those employees who crossed the predefined CIS cutoff of $>76$ at follow-up and had a delta CIS $\leq 8$ were excluded from the analysis. Therefore, after exclusion of prevalent fatigue cases and additional 66 incident cases (53 men and 13 women) with a small change, 5036 men and 1787 women remained for the analysis. After exclusion of the prevalent cases, the results presented here for psychological distress are based on 5243 men and 1785 women.

In the first step of the logistic regression analysis, we adjusted for age, educational level, living alone, employment status, and presence of disease; in step two, we controlled for the other lifestyle factors. In the third step, we adjusted for those psychosocial work characteristics that were identified as risk factors for fatigue or psychological distress. ${ }^{9}$ In addition, we controlled for all psychosocial work characteristics together. Because fatigue and psychological distress are fairly well associated, in the fourth step we controlled for the continuous baseline GHQ-12 or CIS score, when subsequent fatigue or psychological distress was considered as a dependent variable, respectively. ORs and their 95\% CIs were calculated for each lifestyle factor.

\section{Results}

Prevalence of Fatigue and Psychological Distress by Different Categories of Lifestyle Factors at Baseline

The distribution of lifestyle factors and the corresponding prevalence of fatigue and psychological distress can be seen in Table 1. In both genders, those employees who smoked and reported no/once a week physical activity had a significantly higher prevalence of fatigue and psychological distress. Obesity and overweight compared with normal weight were related to fatigue and psychological distress in men only. Employees of both genders who reported no alcohol consumption had a significantly higher prevalence of fatigue compared with those who reported 1 to 14 glasses of alcohol per week.

\section{Intercorrelations of Study Variables}

In both genders, the highest correlation was found between smoking and education $(\mathrm{r}=-0.22, n=7959$, $P<0.01$ in men; $\mathrm{r}=-0.22, n=$ 2682, $P<0.01$ in women). Overall, the study variables were rather weakly correlated with each other (specific data not shown).

\section{Lifestyle Factors at Baseline Predicting Fatigue After 1-Year Follow-Up}

The cumulative incidence of fatigue during 1-year follow-up was $9.7 \%(n=492)$ in men and $13.5 \%(n$ $=241$ ) in women. Because ORs after adjustment for those psychosocial work characteristics that were previously identified as risk factors for fatigue did not vary meaningfully from ORs after adjustment for all psychosocial work characteristics (see description of step 3 in data analytic procedure above), we present only the ORs adjusted for identified risk factors.

As presented in Table 2, in men, all studied lifestyle factors except smoking were significantly associated with fatigue when controlling for demographics, presence of disease, and other lifestyle factors. After adjustment for psychosocial work characteristics, a strong inverse association was found between physical activity and fatigue, whereas the ORs 
TABLE 2

Prospective Associations Between Lifestyle Factors at Baseline and Onset of Fatigue After 1-Year Follow-Up in Men $(n=$ 5036; incident cases, $n=492)$, Adjusted for Potential Confounders and Baseline General Health Questionnaire Score*

\begin{tabular}{|c|c|c|c|c|c|c|c|c|}
\hline \multirow[b]{2}{*}{ Factor } & \multicolumn{2}{|c|}{ OR1 } & \multicolumn{2}{|c|}{ OR2 } & \multicolumn{2}{|c|}{ OR3 } & \multicolumn{2}{|c|}{ OR4 } \\
\hline & OR & $\mathbf{C l}$ & OR & $\mathrm{Cl}$ & OR & Cl & OR & $\mathrm{Cl}$ \\
\hline \multicolumn{9}{|l|}{ Body mass index } \\
\hline Underweight $(<18.5)$ & 1.46 & $0.33-6.54$ & 1.36 & $0.30-6.12$ & 1.29 & $0.28-5.96$ & 1.70 & $0.37-7.83$ \\
\hline Normal (18.5-24.9) & & $1^{\dagger}$ & & $1^{\dagger}$ & & $1^{\dagger}$ & & $1^{\dagger}$ \\
\hline Overweight (25-29.9) & 1.24 & $1.01-1.52$ & 1.24 & $1.01-1.53$ & 1.23 & $1.00-1.53$ & 1.33 & $1.07-1.66$ \\
\hline Obesity ( $\geq 30$ ) & 1.45 & $0.99-2.11$ & 1.30 & $0.88-1.91$ & 1.08 & $0.72-1.62$ & 1.18 & $0.76-1.76$ \\
\hline \multicolumn{9}{|l|}{ Alcohol } \\
\hline $\begin{array}{l}\text { No alcohol } \\
1-14 \text { glasses/week }\end{array}$ & 1.37 & $1^{1.09-1.73}$ & 1.33 & $1^{1.05-1.68}$ & 1.27 & $1^{0.98-1.61}$ & 1.29 & $1^{1.00-1.66}$ \\
\hline 15-21 glasses/week & 1.15 & $0.83-1.57$ & 1.11 & $0.81-1.53$ & 1.12 & $0.81-1.57$ & 1.09 & $0.78-1.53$ \\
\hline$\geq 22$ glasses/week & 0.96 & $0.56-1.64$ & 0.91 & $0.53-1.56$ & 0.91 & $0.53-1.56$ & 0.94 & $0.56-1.63$ \\
\hline \multicolumn{9}{|l|}{ Smoking/daily } \\
\hline No & \multicolumn{2}{|r|}{$1^{\dagger}$} & \multicolumn{2}{|r|}{$1^{\dagger}$} & \multicolumn{2}{|r|}{$1^{\dagger}$} & \multicolumn{2}{|r|}{$1^{\dagger}$} \\
\hline Yes & 1.27 & $1.02-1.57$ & 1.22 & $0.98-1.52$ & 1.20 & $0.96-1.50$ & 1.20 & $0.95-1.52$ \\
\hline \multicolumn{9}{|l|}{ Physical activity } \\
\hline $0-1$ time/week & 1.44 & $1.18-1.77$ & 1.36 & $1.11-1.68$ & 1.37 & $1.10-1.70$ & 1.33 & $1.07-1.66$ \\
\hline 2-7 times/week & & $1^{\dagger}$ & & $1^{\dagger}$ & & $1^{\dagger}$ & & $1^{\dagger}$ \\
\hline$>7$ times/week & 0.78 & $0.52-1.18$ & 0.79 & $0.52-1.19$ & 0.79 & $0.52-1.22$ & 0.88 & $0.57-1.35$ \\
\hline
\end{tabular}

* OR1, adjusted for age, education, living alone, employment status, and presence of disease; OR2, adjusted for step $1+$ other life style factors (body mass index continuous); OR3, adjusted for step 2 + psychosocial work characteristics (psychological demands, decision latitude, physically demanding work, emotional demands); OR4, adjusted for step 3 + baseline General Health Questionnaire score. OR, odds ratio; $\mathrm{Cl}$, confidence interval.

† Reference category.

for no alcohol consumption and being overweight were reduced in size and were marginally significant. When also controlling for baseline GHQ score, being overweight (OR, $1.33 ; 95 \%$ CI, 1.07 to 1.66 ) and not being physically active (OR, 1.33; 95\% CI, 1.07 to 1.66$)$ were predictive for the onset of fatigue after 1-year follow-up. Although other categories of body mass index and physical activity were found to be nonsignificant (eg, being obese or being physically active > seven times per week), the direction of the observed associations, positive or inverse, was as expected. Furthermore, no alcohol consumption (OR, 1.29; $95 \% \mathrm{CI}, 1.00$ to 1.66 ) was predictive of fatigue after adjustment for baseline GHQ score. In women, only being underweight (OR, 3.16; 95\% CI, 1.56 to 6.39 ) was a strong predictor for the onset of fatigue after 1-year follow-up, even after adjustment for potential confounding variables and baseline GHQ score (Table 3 ). Although being physically active was not significantly associated with the development of fatigue, the direction of the associations was as expected.

\section{Lifestyle Factors at Baseline Predicting Psychological Distress After 1-Year Follow-Up}

The 1-year cumulative incidence of psychological distress was $12.6 \%$ $(n=657)$ in men and $18.2 \%(n=$ 321) in women. The presented ORs were adjusted only for psychosocial work characteristics, which were identified as risk factors for psychological distress, because these ORs did not vary meaningfully from those controlled for all psychosocial work characteristics. In contrast to fatigue, the consumption of 15 to 21 glasses of alcohol per week (OR, 1.36; 95\% CI, 1.04 to 1.79 ) was a predictor for the onset of psychological distress in men, even after adjustment for all potential confounding variables and the baseline CIS score (Table 4). Not being physically active, however, was no longer associated with the onset of psychological distress when controlled for baseline CIS score. As shown in Table 5, in women, no lifestyle factor was found to be predictive for the onset of psychological distress after 1-year follow-up.

\section{Discussion}

The findings of this prospective, longitudinal study showed that several modifiable lifestyle factors were significant risk factors for the onset of fatigue and psychological distress in the working population. The identified lifestyle factors were still predictive of fatigue or psychological distress after controlling for other lifestyle factors, psychosocial work characteristics, and baseline outcome measures. In addition, our study suggests some differential effects of lifestyle factors in the onset of fatigue and psychological distress and revealed differences between men and women.

We found evidence for a strong relationship between the lowest level of physical activity during leisure time and fatigue in men, which is consistent with a finding among 


\section{TABLE 3}

Prospective Associations Between Lifestyle Factors at Baseline and Onset of Fatigue After 1-Year Follow-Up in Women ( $n=1787$; incident cases, $n=241)$, Adjusted for Potential Confounders and Baseline General Health Questionnaire Score*

OR1

OR2

OR3

OR4

\begin{tabular}{|c|c|c|c|c|c|c|c|c|}
\hline Factor & OR & $\mathbf{C l}$ & OR & $\mathbf{C l}$ & OR & Cl & OR & $\mathbf{C l}$ \\
\hline \multicolumn{9}{|l|}{ Body mass index } \\
\hline Underweight $(<18.5)$ & 3.14 & $1.57-6.28$ & 3.10 & $1.55-6.22$ & 3.20 & $1.58-6.47$ & 3.16 & $1.56-6.39$ \\
\hline Normal (18.5-24.9) & \multicolumn{2}{|r|}{$1^{\dagger}$} & \multicolumn{2}{|r|}{$1^{\dagger}$} & \multicolumn{2}{|r|}{$1^{\dagger}$} & \multicolumn{2}{|r|}{$1^{\dagger}$} \\
\hline Overweight (25-29.9) & 1.16 & $0.80-1.67$ & 1.16 & $0.80-1.68$ & 1.16 & $0.80-1.68$ & 1.22 & $0.84-1.78$ \\
\hline Obesity ( $\geq 30$ ) & 1.50 & $0.85-2.67$ & 1.51 & $0.85-2.68$ & 1.62 & $0.90-2.89$ & 1.66 & $0.93-2.98$ \\
\hline \multicolumn{9}{|l|}{ Alcohol } \\
\hline No alcohol & 1.02 & $0.76-1.37$ & 1.01 & $0.75-1.36$ & 0.99 & $0.73-1.33$ & 0.99 & $0.73-1.34$ \\
\hline 1-14 glasses/week & \multicolumn{2}{|r|}{$1^{\dagger}$} & \multicolumn{2}{|r|}{$1^{\dagger}$} & \multicolumn{2}{|r|}{$1^{\dagger}$} & \multicolumn{2}{|r|}{$1^{\dagger}$} \\
\hline 15-21 glasses/week & 0.72 & $0.28-1.86$ & 0.67 & $0.26-1.74$ & 0.65 & $0.25-1.71$ & 0.68 & $0.26-1.79$ \\
\hline$\geq 22$ glasses/week & 0.05 & $0.00-$ & 0.05 & $0.00-$ & 0.05 & $0.00-$ & 0.06 & $0.00-$ \\
\hline \multicolumn{9}{|l|}{ Smoking/daily } \\
\hline No & \multicolumn{2}{|r|}{$1^{\dagger}$} & \multicolumn{2}{|r|}{$1^{\dagger}$} & \multicolumn{2}{|r|}{$1^{\dagger}$} & \multicolumn{2}{|r|}{$1^{\dagger}$} \\
\hline Yes & 1.34 & $0.97-1.86$ & 1.37 & $0.98-1.91$ & 1.38 & $0.99-1.92$ & 1.33 & $0.95-1.86$ \\
\hline \multicolumn{9}{|l|}{ Physical Activity } \\
\hline $0-1$ time/week & 1.22 & $0.90-1.65$ & 1.13 & $0.82-1.54$ & 1.10 & $0.80-1.51$ & 1.05 & $0.76-1.44$ \\
\hline 2-7 times/week & \multicolumn{2}{|r|}{$1^{\dagger}$} & \multicolumn{2}{|r|}{$1^{\dagger}$} & \multicolumn{2}{|r|}{$1^{\dagger}$} & \multicolumn{2}{|r|}{$1^{\dagger}$} \\
\hline$>7$ times/week & 0.73 & $0.37-1.45$ & 0.73 & $0.37-1.46$ & 0.75 & $0.38-1.50$ & 0.74 & $0.37-1.48$ \\
\hline
\end{tabular}

* OR1, adjusted for age, education, living alone, employment status, and presence of disease; OR2, adjusted for step $1+$ other life style factors (body mass index continuous); OR3, adjusted for step 2 + psychosocial work characteristics (coworker social support); OR4, adjusted for step 3 + baseline General Health Questionnaire score. OR, odds ratio; Cl, confidence interval.

${ }^{\dagger}$ Reference category.

\section{TABLE 4}

Prospective Associations Between Lifestyle Factors at Baseline and Onset of Psychological Distress After 1-Year FollowUp in Men ( $n=5243$; incident cases, $n=657$ ), Adjusted for Potential Confounders and Baseline Checklist Individual Strength Score*

\begin{tabular}{|c|c|c|c|c|c|c|c|c|}
\hline \multirow[b]{2}{*}{ Factor } & \multicolumn{2}{|c|}{ OR1 } & \multicolumn{2}{|c|}{ OR2 } & \multicolumn{2}{|c|}{ OR3 } & \multicolumn{2}{|c|}{ OR4 } \\
\hline & OR & $\mathbf{C l}$ & OR & $\mathbf{C l}$ & OR & $\mathbf{C l}$ & OR & $\mathbf{C l}$ \\
\hline \multicolumn{9}{|l|}{ Body mass index } \\
\hline Underweight $(<18.5)$ & 0.38 & $0.05-2.90$ & 0.37 & $0.05-2.79$ & 0.36 & $0.05-2.77$ & 0.43 & $0.06-3.30$ \\
\hline Normal (18.5-24.9) & \multicolumn{2}{|r|}{$1^{\dagger}$} & \multicolumn{2}{|r|}{$1^{\dagger}$} & \multicolumn{2}{|r|}{$1^{\dagger}$} & \multicolumn{2}{|r|}{$1^{\dagger}$} \\
\hline Overweight (25-29.9) & 1.07 & $0.90-1.28$ & 1.07 & $0.89-1.28$ & 0.98 & $0.82-1.18$ & 0.98 & $0.81-1.19$ \\
\hline Obesity $(\geq 30)$ & 0.90 & $0.62-1.32$ & 0.85 & $0.58-1.24$ & 0.69 & $0.46-1.04$ & 0.68 & $0.45-1.02$ \\
\hline \multicolumn{9}{|l|}{ Alcohol } \\
\hline No alcohol & 1.21 & $0.98-1.50$ & 1.19 & $0.96-1.48$ & 1.14 & $0.92-1.43$ & 1.14 & $0.91-1.44$ \\
\hline 1-14 glasses/week & \multicolumn{2}{|r|}{$1^{\dagger}$} & \multicolumn{2}{|r|}{$1^{\dagger}$} & \multicolumn{2}{|r|}{$1^{\dagger}$} & \multicolumn{2}{|r|}{$1^{\dagger}$} \\
\hline 15-21 glasses/week & 1.39 & $1.07-1.80$ & 1.34 & $1.02-1.75$ & 1.36 & $1.04-1.78$ & 1.36 & $1.04-1.79$ \\
\hline$\geq 22$ glasses/week & 1.13 & $0.73-1.73$ & 1.13 & $0.73-1.74$ & 1.08 & $0.70-1.68$ & 1.00 & $0.64-1.56$ \\
\hline \multicolumn{9}{|l|}{ Smoking/daily } \\
\hline No & \multicolumn{2}{|c|}{$1^{\dagger}$} & \multicolumn{2}{|r|}{$1^{\dagger}$} & \multicolumn{2}{|r|}{$1^{\dagger}$} & \multicolumn{2}{|r|}{$1^{\dagger}$} \\
\hline Yes & 1.10 & $0.91-1.34$ & 1.03 & $0.84-1.26$ & 1.00 & $0.81-1.22$ & 1.02 & $0.83-1.26$ \\
\hline \multicolumn{9}{|l|}{ Physical Activity } \\
\hline 0-1 time/week & 1.32 & $1.11-1.58$ & 1.28 & $1.07-1.54$ & 1.24 & $1.03-1.50$ & 1.06 & $0.87-1.29$ \\
\hline 2-7 times/week & \multicolumn{2}{|c|}{$1^{\dagger}$} & \multicolumn{2}{|r|}{$1^{\dagger}$} & \multicolumn{2}{|r|}{$1^{\dagger}$} & \multicolumn{2}{|c|}{$1^{\dagger}$} \\
\hline$>7$ times/week & 1.00 & $0.72-1.40$ & 0.99 & $0.71-1.38$ & 0.97 & $0.69-1.36$ & 1.02 & $0.72-1.44$ \\
\hline
\end{tabular}

* OR1, adjusted for age, education, living alone, employment status, and presence of disease; OR2, adjusted for step $1+$ other life style factors (body mass index continuous); OR3, adjusted for step $2+$ psychosocial work characteristics (psychological demands, physically demanding work, emotional demands, conflict supervisor, conflict coworker); OR4, adjusted for step 3 + baseline Checklist Individual Strength score. OR, odds ratio; $\mathrm{Cl}$, confidence interval.

${ }^{\dagger}$ Reference category.

male industrial employees reported in a cross-sectional study by KristalBoneh et al. ${ }^{1}$ In contrast to Kristal-
Boneh et al, ${ }^{1}$ our study revealed that overweight and no alcohol consumption are risk factors for the onset of fatigue, whereas smoking was not prospectively associated with fatigue in men. With respect to psychologi- 


\section{TABLE 5}

Prospective Associations Between Lifestyle Factors at Baseline and Onset of Psychological Distress After 1-Year FollowUp in Women ( $n=1785$; incident cases, $n=321)$, Adjusted for Potential Confounders and Baseline Checklist Individual Strength Score*

\begin{tabular}{|c|c|c|c|c|c|c|c|c|}
\hline \multirow[b]{2}{*}{ Factor } & \multicolumn{2}{|c|}{ OR1 } & \multicolumn{2}{|c|}{ OR2 } & \multicolumn{2}{|c|}{ OR3 } & \multicolumn{2}{|c|}{ OR4 } \\
\hline & OR & Cl & OR & $\mathrm{Cl}$ & OR & $\mathrm{Cl}$ & OR & $\mathrm{Cl}$ \\
\hline \multicolumn{9}{|l|}{ Body mass index } \\
\hline Underweight $(<18.5)$ & 1.60 & $0.76-3.37$ & 1.53 & $0.72-3.23$ & \multirow{2}{*}{\multicolumn{2}{|c|}{$* \neq$}} & 1.32 & $0.60-2.91$ \\
\hline Normal (18.5-24.9) & \multicolumn{2}{|r|}{$1^{\dagger}$} & \multicolumn{2}{|r|}{$1^{\dagger}$} & & & \multicolumn{2}{|r|}{$1^{\dagger}$} \\
\hline Overweight (25-29.9) & 1.15 & $0.84-1.57$ & 1.15 & $0.84-1.59$ & & & 1.14 & $0.82-1.58$ \\
\hline Obesity $(\geq 30)$ & 1.39 & $0.82-2.34$ & 1.42 & $0.84-2.41$ & & & 1.43 & $0.84-2.45$ \\
\hline \multicolumn{9}{|l|}{ Alcohol } \\
\hline No alcohol & 0.86 & $0.66-1.12$ & 0.86 & $0.66-1.12$ & \multirow{4}{*}{\multicolumn{2}{|c|}{ *‡ }} & 0.83 & $0.63-1.09$ \\
\hline 1-14 glasses/week & \multicolumn{2}{|r|}{$1^{\dagger}$} & \multicolumn{2}{|r|}{$1^{\dagger}$} & & & & $1^{\dagger}$ \\
\hline 15-21 glasses/week & 0.92 & $0.45-1.88$ & 0.85 & $0.41-1.74$ & & & 0.83 & $0.40-1.71$ \\
\hline$\geq 22$ glasses/week & 0.03 & $0.00-$ & 0.03 & $0.00-$ & & & 0.01 & $0.00-$ \\
\hline \multicolumn{9}{|l|}{ Smoking/daily } \\
\hline No & \multicolumn{2}{|c|}{$1^{\dagger}$} & \multicolumn{2}{|c|}{$1^{\dagger}$} & \multirow{2}{*}{\multicolumn{2}{|c|}{ *‡ }} & \multicolumn{2}{|r|}{$1^{\dagger}$} \\
\hline Yes & 1.30 & $0.97-1.74$ & 1.27 & $0.94-1.72$ & & & 1.20 & $0.88-1.64$ \\
\hline \multicolumn{9}{|l|}{ Physical Activity } \\
\hline $0-1$ time/week & 1.15 & $0.88-1.52$ & 1.13 & $0.85-1.49$ & \multirow{3}{*}{\multicolumn{2}{|c|}{$* \ddagger$}} & 1.01 & $0.76-1.35$ \\
\hline 2-7 times/week & \multicolumn{2}{|r|}{$1^{\dagger}$} & \multicolumn{2}{|r|}{$1^{\dagger}$} & & & & $1^{\dagger}$ \\
\hline$>7$ times/week & 0.81 & $0.44-1.50$ & 0.82 & $0.44-1.52$ & & & 0.89 & $0.47-1.67$ \\
\hline
\end{tabular}

* OR1, adjusted for age, education, living alone, employment status, and presence of disease; OR2, adjusted for step $1+$ other life style factors (body mass index continuous); OR4, adjusted for step 2 + baseline Checklist Individual Strength score. OR, odds ratio; Cl, confidence interval.

${ }^{\dagger}$ Reference category.

‡ OR3, no adjustment for psychosocial work characteristics.

cal distress, Stansfeld et al ${ }^{10}$ also reported in a cross-sectional study that the proportion of GHQ cases increased with alcohol intake in men (and in women). In the same study, Stansfeld et $\mathrm{al}^{10}$ showed that smoking habit, which was not predictive of distress in our study, was found to be related to psychiatric morbidity in men only. A comparison of these cross-sectional results with our prospective findings, however, is hampered because of a different definition of lifestyle factors, fatigue and psychological distress, a different nature of designs, different time spans, and different settings in which the studies were performed. Regarding differential etiological effects of lifestyle in fatigue and psychological distress, we should acknowledge that our results suggest distinct factors in both health outcomes and in both genders.

When interpreting the results of the present study, several methodological issues must be considered. One issue concerns a possible mis- classification of exposure and the measurement of the examined lifestyle factors. If misclassification has occurred, we expect this to be nondifferential, and estimates are most likely biased toward the null value. The body mass index was categorized according to the standard classification of the National Institutes of Health. ${ }^{20}$ Although small in sample size, underweight employees were neither excluded from the present study nor classified as reporting a normal weight. Nevertheless, we must recognize that it is not impossible that, for instance, an underlying disease can account for the established causal relation with psychological distress in women. Daily smoking, alcohol consumption per week, and engagement in physical activity of at least half an hour per week (eg, exercise, biking, walking) were assessed by a single item. The items, however, had response categories that can easily be interpreted and can be used directly to develop measures and actions to prevent, or at least reduce, the risk of fatigue and psychological distress in the working population.

Following on this issue, a possible misclassification of fatigue or psychological distress cases cannot be excluded, because both outcome measures were dichotomized. However, the CIS cutoff point of $>76$ for fatigue, which was empirically derived in a separate pilot study, had a high sensitivity and specificity ( $73 \%$ and $90 \%$, respectively), ${ }^{19}$ thereby restricting misclassification. Moreover, in the present study, we also applied an additional conservative strategy by introducing a refinement of a minimum amount of increase on crossing the cutoff, thereby excluding those employees who are close to the cutoff and cause only a small change. With respect to psychological distress, the threshold for case classification (GHQ $\geq 4$ ) is high but likely to indicate very symptomatic employees as probable cases of minor psychiatric disorder, and in that way, minimize possible misclassification. 
Whereas in men and women different lifestyle factors were observed to be predictive of fatigue, no significant predictors albeit trends were found for future psychological distress in women. Whether this gender difference can be attributed to a small sample size or a different time course of lifestyle factors in affecting health cannot yet be determined and requires further exploration.

Another issue concerns the follow-up period of 1 year between the assessment of lifestyle factors and fatigue and psychological distress. However, because we identified several lifestyle factors as risk factors for the development of fatigue and psychological distress, it is unlikely that with the two outcomes studied, the follow-up period of 1 year was too short. Moreover, it has been argued that different stressors follow different exposure time courses in longitudinal studies on work stress. ${ }^{34}$ Accordingly, we should acknowledge that the impact of each lifestyle factor on fatigue and psychological distress may follow a different time course. Although in some factors a high prevalence of fatigue and psychological distress was observed, the cumulative incidence of fatigue and psychological distress after 1-year follow-up was rather low (eg, smoking). Given the cross-sectional association, the question is raised whether causal dynamics have played themselves out, ie, there is no continued impact of continued exposure. Hence, to explore the exposure time concept of each lifestyle factor and to clarify the impact of changes in lifestyle factors on the onset of fatigue and psychological distress, repeated measurements during a longer follow-up period, different time frames, or both, are required.

Given the considerable impact of fatigue and psychological distress on socioeconomic costs and the high prevalence of potentially modifiable lifestyle factors within our large, heterogeneous working population, it is important to note that the prospective results suggest causal associations.
Although prevention of mental health problems is difficult, these findings are extremely valuable and provide a sound basis for the development of recommendations and interventions for improving mental health, either on an individual or a group level (eg, at the workplace). For instance, being physically inactive during leisure time, a prevalent and modifiable lifestyle factor, was found to be a strong, independent predictor of fatigue after 1-year follow-up in men, even after the adjustment for psychosocial work characteristics. Thus, the benefits of increased physical activity during leisure time are strongly suggested. Nevertheless, it should be remembered that if a cross-sectional association but no association over time (eg, smoking) exists, the benefits of changing the risk factor cannot be ruled out.

To conclude, this prospective study revealed that potentially modifiable lifestyle factors are predictive of fatigue and psychological distress in men and women. These effects are independent of other lifestyle factors, psychosocial work characteristics, and baseline measures of psychological distress and fatigue. Moreover, it suggests some differential effects of lifestyle factors in the etiology of fatigue and psychological distress, supporting the notion of distinct concepts. Notably, from the viewpoint of developing measures to prevent or at least reduce the risk of fatigue and psychological distress in the working population, the study revealed modifiable risk factors. Therefore, the results can be used to design interventions, either individually tailored or at the group level in the workplace. Nevertheless, to completely understand the multifactorial etiology of fatigue and psychological distress and to obtain conclusive evidence for distinct concepts, future research should further elucidate the role of work-family factors and individual characteristics and their interplay with lifestyle factors and psychosocial work characteristics.

\section{Acknowledgments}

The Maastricht Cohort Study is part of the Netherlands concerted research action on "Fatigue at Work" granted by the Netherlands Organization for Scientific Research. The present study was and is currently supported by a grant from the Netherlands Organization for Scientific Research (NWO grant no. 580-02.251).

\section{References}

1. Kristal-Boneh E, Froom P, Harari G, Ribak J. Fatigue among Israeli industrial employees. J Occup Environ Med. 1996; 38:1145-1150.

2. Meijman T, Schaufeli W. Psychische vermoeidheid en arbeid. Ontwikkelingen in de A\&O-psychologie [Fatigue at work. Developments in I/O psychology]. De Psycholoog. 1996; June:236-241.

3. Hardy GE, Shapiro DA, Borrill CS. Fatigue in the workforce of National Health Service Trusts: levels of symptomatology and links with minor psychiatric disorder, demographic, occupational and work role factors. J Psychosom Res. 1997;43:8392.

4. Mounstephen A, Sharpe M. Chronic fatigue syndrome and occupational health. Occup Med (Oxf). 1997;47:217-227.

5. Schröer CAP. De toename van arbeidsongeschiktheid wegens psychische aandoeningen [The increase of work disability due to mental disorders]. $T B V$. 1997;5:16-23.

6. Lewis G, Wessely S. The epidemiology of fatigue: more questions than answers. J Epidemiol Community Health. 1992;46: 92-97.

7. Pawlikowska T, Chalder T, Hirsch SR, Wallace P, Wright DJ, Wessely SC. Population based study of fatigue and psychological distress. BMJ. 1994;308;763766.

8. Bültmann U, Kant IJ, van Amelsvoort LGPM, van den Brandt PA, Kasl SV. Differences in fatigue and psychological distress across occupations: results from The Maastricht Cohort Study of Fatigue at Work. J Occup Environ Med. 2001;43: 976-983.

9. Bültmann U, Kant IJ, Van den Brandt PA, Kasl SV. Psychosocial work characteristics as risk factors for the onset of fatigue and psychological distress: prospective results from the Maastricht Cohort Study. Psychol Med. In press.

10. Stansfeld SA, Smith GD, Marmot M. Association between physical and psychological morbidity in the Whitehall II Study. J Psychosom Res. 1993;37:227238 .

11. Lasser K, Boyd JW, Woolhandler S, Himmelstein DU, McCormick D, Bor DH. Smoking and mental illness: a population-based prevalence study. JAMA. 2000;284:2606-2610. 
12. Bültmann U, Kant IJ, Kasl S, Beurskens A, Van den Brandt P. Fatigue and psychological distress in the working population: psychometrics, prevalence, and correlates. J Psychosom Res. In press.

13. Hickie IB, Hooker AW, Hadzi Pavlovic D, Bennett BK, Wilson AJ, Lloyd AR. Fatigue in selected primary care settings: sociodemographic and psychiatric correlates. Med J Aust. 1996;164:585-588.

14. Hickie I, Koschera A, Hadzi-Pavlovic D, Bennett B, Lloyd A. The temporal stability and co-morbidity of prolonged fatigue: a longitudinal study in primary care. Psychol Med. 1999;29:855-861.

15. Van der Linden G, Chalder T, Hickie I, Koschera A, Sham P, Wessely S. Fatigue and psychiatric disorder: different or the same? Psychol Med. 1999;29:863-868.

16. Koschera A, Hickie I, Hadzi-Pavlovic D, Wilson A, Lloyd A. Prolonged fatigue, anxiety and depression: exploring relationships in a primary care sample. Aust N Z J Psychiatry. 1999;33:545-552.

17. Addington AM, Gallo JJ, Ford DE, Eaton WW. Epidemiology of unexplained fatigue and major depression in the community: the Baltimore ECA follow-up, 1981 to 1994. Psychol Med. 2001;31: 1037-1044.

18. Kant IJ, Beurskens A, Schröer C, Nijhuis F, van Schayck C, Swaen G. De Maastrichtse Cohort Studie naar langdurige psychische vermoeidheid in de arbeidssituatie [The Maastricht Cohort Study of prolonged Fatigue at Work]. TBV. 2000; 8:226-232.

19. Bültmann U, De Vries M, Beurskens AJHM, Bleijenberg G, Vercoulen JHMM, Kant IJ. Measurement of prolonged fatigue in the working population: determination of a cutoff point for the
Checklist Individual Strength. J Occup Health Psychol. 2000;5:411-416.

20. National Institutes of Health. Clinical Guidelines on the Identification, Evaluation, and Treatment of Overweight and Obesity in Adults-The Evidence Report. Bethesda, MD: US Department of Health and Human Services; 1998. NIH publication no.98-4083.

21. Karasek RA. Job Content Questionnaire and Users's Guide. Los Angeles: University of Southern California, Department of Industrial and Systems Engineering; 1985.

22. Houtman I. Reliability and Validity of the Dutch Version of the Karasek Job Content Questionnaire: Proceedings of the NIOSH/APA Conference on Stress, Work, and Health. Washington, DC: NIOSH/ APA; 1995.

23. Gründemann R, Smulders $P$, de Winter C. Handleiding Vragenlijst Arbeid en Gezondheid [Questionnaire on Work and Health. Manual]. Lisse: Swets \& Zeitlinger; 1993.

24. Van Veldhoven M, Meijman T. Het meten van psychosociale arbeidsbelasting met een vragenlijst: De Vragenlijst Beleving en Beoordeling van de Arbeid (VBBA) [Questionnaire on Perception and Judgement of Work]. Amsterdam: Nederlands Instituut voor Arbeidsomstandigheden; 1994.

25. Vercoulen JH, Swanink CM, Fennis JF, Galama JM, van der Meer JW, Bleijenberg G. Dimensional assessment of chronic fatigue syndrome. $J$ Psychosom Res. 1994;38:383-392.

26. Vercoulen JHHM, Alberts M, Bleijenberg G. De Checklist Individuele Spankracht (CIS) [The Checklist Individual Strength (CIS)]. Gedragstherapie. 1999; $32: 131-136$
27. Vercoulen JH, Hommes OR, Swanink $\mathrm{CM}$, et al. The measurement of fatigue in patients with multiple sclerosis. A multidimensional comparison with patients with chronic fatigue syndrome and healthy subjects. Arch Neurol. 1996;53: 642-649.

28. Vercoulen JH, Swanink CM, Fennis JF, Galama JM, van der Meer JW, Bleijenberg G. Prognosis in chronic fatigue syndrome: a prospective study on the natural course. J Neurol Neurosurg Psychiatry. 1996;60:489-494.

29. Beurskens AJ, Bültmann U, Kant IJ, Vercoulen JH, Bleijenberg G, Swaen GM. Fatigue among working people: validity of a questionnaire measure. Occup Environ Med. 2000;57:353-357.

30. Goldberg DP, Williams P. A User's Guide to the General Health Questionnaire. Windsor: NFER-Nelson; 1988.

31. Koeter MWJ, Ormel J. General Health Questionnaire, Handleiding Nederlandse bewerking [General Health Questionnaire, Manual Dutch version]. Lisse: Swets \& Zeitlinger; 1991.

32. Wall TD, Bolden RI, Borrill CS, et al. Minor psychiatric disorder in NHS trust staff: occupational and gender differences. Br J Psychiatry. 1997;171:519523.

33. Statistical Package for the Social Sciences. SPSS for Windows, release 9.0. Chicago: Statistical Products and Service Solutions; 1998.

34. Frese M, Zapf D. Methodological issues in the study of work stress: objective vs subjective measurement of work stress and the question of longitudinal studies. In: Cooper CL, Payne R, eds. Causes, Coping, and Consequences of Stress at Work. Chichester: Wiley; 1988:375-411. 